\title{
Signo de la arteria cerebral media hiperdensa
}

\section{Hyperdense Middle Cerebral Artery Sign}

\author{
Jacqueline Miklaszewski ${ }^{1}$ Laura C. Garcia ${ }^{1}$ Cristina Afione ${ }^{1}$ \\ ${ }^{1}$ Diagnóstico por Imágenes, Sanatorio Güemes, Ciudad Autónoma de \\ Buenos Aires, Argentina \\ Rev Argent Radiol 2022;85(Suppl S1):S13-S14. \\ Address for correspondence Jacqueline Miklaszewski, MD, \\ Diagnóstico por Imágenes, Sanatorio Güemes, Francisco Acuña de \\ Figueroa 1240, 1180AAD, CABA, Ciudad Autónoma de Buenos Aires, \\ Argentina (e-mail: jackiemikla@gmail.com).
}

El signo de la arteria cerebral media hiperdensa (SACMH), en tomografía computada (TC) de cerebro sin contraste (-Fig. 1), fue descripto por primera vez por G. Gács en el año $1983 .^{1}$ Ese hallazgo corresponde al aumento de la densidad en tomografía computada sin contraste de la arteria cerebral media (ACM) en su segmento $M 1$, en comparación con su homóloga contralateral y se debe a la presencia de un trombo oclusivo en la luz del vaso.

$\mathrm{Su}$ importancia radica en que es un signo precoz de accidente cerebro-vascular (ACV) isquémico, visible dentro de los 90 minutos de inicio del cuadro.

\section{Características Fisiopatológicas}

El SACMH se manifiesta como un aumento de la atenuación tomográfica de la arteria cerebral media debido a la presencia de mayor cantidad de fibrina y proteínas que, asociado a una menor proporción de suero, presenta una mayor densidad (80UH $=$ unidades Hounsfield) que la de la sangre circulante $(40 \mathrm{UH})^{2}$

\section{Hallazgos Imagenológicos}

El SACMH se encuentra entre el $40 \%$ y el $60 \%$ de los pacientes con oclusión de la ACM demostrada con angiografía ( - Fig. 2). En la TC de cerebro sin contraste se evidencia una imagen lineal hiperdensa en el trayecto del segmento M1 de la arteria cerebral media, en comparación con la contralateral, en relación a signos de trombosis del vaso afectado. Existen varios estudios que avalan la importancia de ese signo, ya que se demostró que existen diferencias significativas en la cuantificación absoluta y

received November 2, 2017 accepted April 29, 2018 published online May 23, 2018
DOI https://doi.org/ 10.1055/s-0038-1656540. ISSN 1852-9992. relativa de la densidad del vaso en pacientes con ACV isquémico agudo, en comparación con sujetos normales.,

Si bien la especificidad es cercana al $100 \%$, la sensibilidad y el valor predictivo negativo son bajos, del orden del 27\%-54\% y del 33\%-36\% respectivamente. ${ }^{3,5}$ El SACMH permite identificar la localización de la lesión aun cuando la clínica no sea concluyente. Proporciona además información respecto al pronóstico del paciente, ya que en la mayoría de los casos tiende a desaparecer una semana después del infarto. Su persistencia es interpretada como indicador de mal pronóstico, pues indica un infarto por lo general extenso, en el territorio de la arteria cerebral media., ${ }^{3,5}$ Ese signo también ha sido descripto en la arteria cerebral posterior y arteria basilar en asociación con ACV de esos territorios vasculares. Se han descripto otros signos tomográficos como marcadores de ACV agudo precoz, entre los cuales se destacan: hipodensidad de los ganglios de la base, pérdida de la diferenciación de la interfase sustancia gris-sustancia blanca, hipodensidad difusa del parénquima, borramiento de surcos corticales e hipoatenuación del ribete insular. ${ }^{4,5}$

Cabe destacar que, durante las primeras horas de un evento vascular isquémico cerebral, los hallazgos por TC pueden ser difíciles de detectar aun cuando exista compromiso de un territorio vascular extenso, por lo cual requiere de un adecuado entrenamiento del radiólogo para su correcta identificación.

\section{Diagnósticos Diferenciales}

Los diagnósticos diferenciales pueden observarse en casos de pacientes con hematocrito elevado ya sea por poliglobulia o

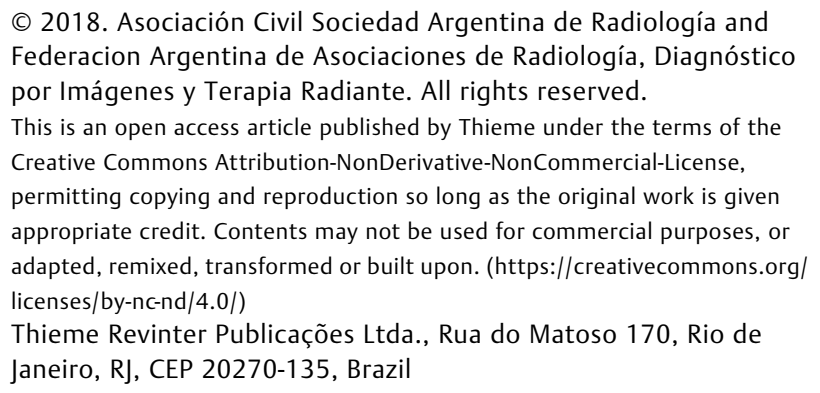




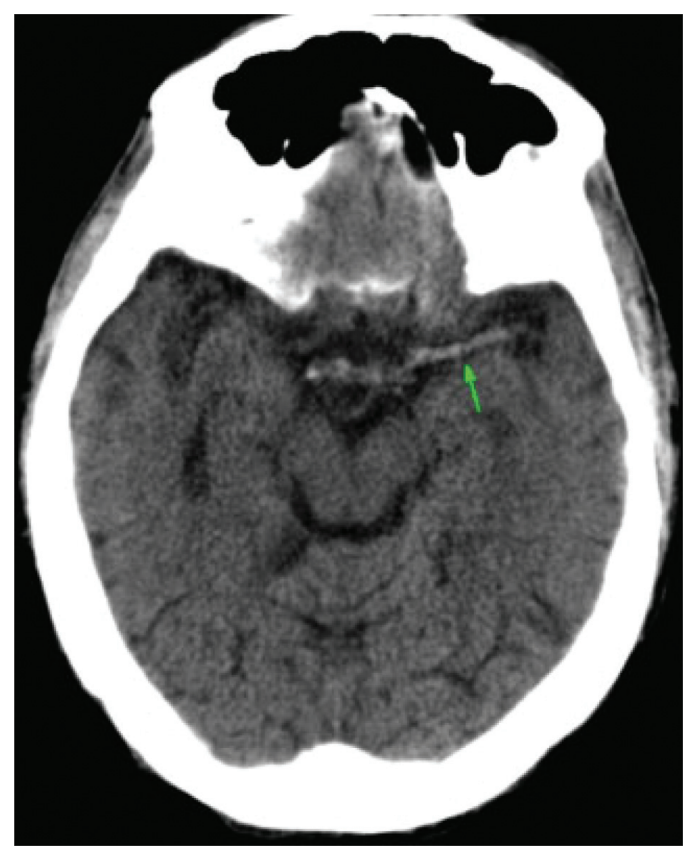

Fig. 1 TC de cerebro sin contraste, corte axial. Se observa hiperdensidad de la arteria cerebral media izquierda en comparación con la contralateral (flecha). Signo de la arteria cerebral media hiperdensa (SACMH).

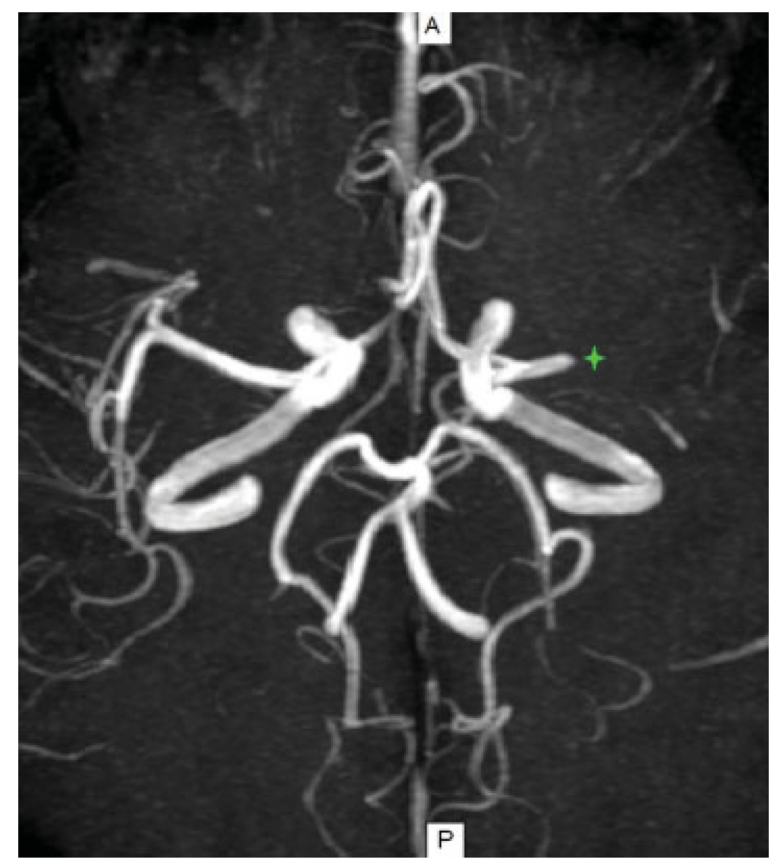

Fig. 2 Angioresonancia de vasos intracraneales. Reconstrucción en máxima intensidad de proyección (MIP), plano axial. Se observa ausencia de señal de flujo en la arteria cerebral media izquierda desde el sector distal del segmento M1, compatible con trombosis oclusiva (asterisco). deshidratación. En esos casos, la hiperdensidad de la ACM se presenta de forma bilateral, lo que facilita el diagnóstico diferencial. La ateromatosis cálcica es otra entidad a tener en cuenta como diagnóstico diferencial, pudiendo ser uni o bilateral; en la mayoría de los casos los valores de atenuación son mayores a los evidenciados en el SACMH por el contenido de calcio.

\section{Conclusión}

La TC es mundialmente aceptada como primer estudio por imágenes ante la sospecha clínica de ACV isquémico agudo. Consideramos de suma importancia que el radiólogo sepa reconocer el SACMH, ya que se trata de un indicador temprano de esa patología. Así, en el contexto multidisciplinario, informar al médico interviniente de ese hallazgo temprano permite instaurar al paciente el tratamiento adecuado con el objetivo de disminuir su morbimortalidad.

\section{Confidencialidad de Los Datos}

Los autores declaran que han seguido los protocolos de su centro de trabajo sobre la publicación de datos de pacientes y que todos los pacientes incluidos en el estudio han recibido información suficiente y han dado su consentimiento informado por escrito.

Protección de Personas y Animales

Los autores declaran que para esta investigación no se han realizado experimentos en seres humanos ni en animales.

\section{Derecho a la Privacidad y Consentimiento Informado} Los autores declaran que en este artículo no aparecen datos de pacientes.

Conflicto de Intereses

Los autores declaran no tener ningún conflicto de intereses.

\section{Bibliografía}

1 Gács G, Fox AJ, Barnett HJ, Vinuela F. CT visualization of intracranial arterial thromboembolism. Stroke 1983;14(05): 756-762

2 Petitti N. The hyperdense middle cerebral artery sign. Radiology 1998;208(03):687-688

3 Abul-Kasim K, Selariu E, Brizzi M, Petersson J. Hyperdense middle cerebral artery sign in multidetector computed tomography: definition, occurrence, and reliability analysis. Neurol India 2009;57(02):143-150

4 Meli F, Vallejos J, Álvarez C, Capuñay C, Carrascosa P. Cuantificación del signo de la arteria cerebral media hiperdensa con TCMD. Rev Argent Radiol 2011;75(04):297-304

5 Carrillo Esper R, Garcilazo Reyes YJ, Lee Cervantes D, Peralta Prado AB, Gonzáles Noris P, Rodriguez Ortiz U. Signo de la arteria cerebral media hiperdensa. Med Int Mex 2012;28(04):384-388 